\title{
Debate PÚblico E FILOSOFIA NO BRASIL
}

Nythamar de Oliveira*

1. Disputas conceituais podem reivindicar, decerto, algum tipo de racionalidade prático-argumentativa capaz de fundamentar a construção de diferentes paradigmas emancipatórios na filosofia política contemporânea. De uma maneira geral, pode-se até dizer que a articulação prático-teórica de um discurso filosófico capaz de seduzir e influenciar ouvintes e cidadãos em suas tomadas de decisão coletivas tem sido tematizada desde os dias áureos de Sócrates, Platão e Aristóteles até as disputationes medievais em suas limitadas experiências de debate público. Todavia, foi somente com o advento e a consolidação da esfera pública moderna que uma ideia propriamente política se enraizou na publicidade (Öffentlichkeit) emancipatória vislumbrada por pensadores iluministas como Rousseau, Hume e Kant, em particular nos salons franceses e coffee houses inglesas na segunda metade do século XVIII.

No início do século XXI, sobretudo logo após os ataques terroristas de 11 de setembro de 2001 perpetrados no coração do mais importante centro cosmopolita do capitalismo global, assistimos a vários debates em torno do problema do universalismo ético e de seu maior rival, o chamado relativismo

\footnotetext{
* Doutor pela State University of New York em Stony Brook (EUA), professor adjunto da Faculdade de Filosofia e Ciências Humanas da Pontifícia Universidade Católica do Rio Grande do Sul (PUC-RS), pesquisador do CNPq e coordenador do Centro Brasileiro de Pesquisas em Democracia.
} 
$|16|$

Debate Público e Filosofia no Brasil...

cultural. Embora o relativismo cultural tenha emergido nos anos 30 do século passado, notadamente em torno de escritos da antropóloga norte-americana Ruth Benedict e da recepção das concepções culturalistas de Franz Boas e Bronislaw Malinowski, foi apenas na segunda metade do século XX que se consolidou em torno de conceitos como globalização e multiculturalismo. Como o Brasil atravessou, de 1964 a 1985, 21 anos de ditadura militar, foi sobretudo a partir dos anos 1980 que o debate público se consolidou no país, em torno de recepções liberais, marxistas e libertárias de autores como Gramsci, Lukács, Habermas, Rawls e Nozick, retomando conceitos fundamentais de filosofia política, tais como democracia, justiça, autonomia e igualdade, contextualizando-os em nossa realidade social.

O mundo globalizado assiste hoje, com atônito entusiasmo, aos eventos que podem derrubar déspotas e tiranos na maior parte dos países árabes na África e no Oriente Médio, abrindo o caminho para novas formas de democracia. Como nós mesmos vivenciamos e aprendemos em nosso país, a democracia só se planta, se cultiva e se consolida pelo povo e para o povo, de quem também emana toda aspiração soberana legítima. No entanto, as desigualdades sociais e econômicas continuam desafiando os processos de democratização no mundo globalizado, apesar de todas as conquistas já alcançadas e de todos os êxitos logrados pelos ideais de justiça, liberdade e igualdade semeados ao longo de várias décadas desde a segunda metade do século passado. O Brasil se insere nesse contexto de conjugação normativa da globalização e da democratização e, desde o início do presente século, o debate público reflete questões de normatividade que também se articulam em outros contextos socioeconômicos e culturais.

2. Foi notadamente a partir dos trabalhos seminais do filósofo político José Arthur Giannotti que vários teóricos e filósofos sociais brasileiros, tais como João Carlos Brum Torres, Sergio Paulo Rouanet, Renato Janine Ribeiro, Zeljko Loparic, Denis Rosenfield e Nelson Boeira, se interessaram em criticar e avaliar em foros de debate público as obras originais de autores contemporâneos como Rawls e Habermas, contribuindo para 
a sua recepção crítica aqui no Brasil. A constante busca de autocompreensão da nossa realidade política e social, para além das desgastadas discussões sobre uma suposta identidade nacional ou uma cultura política monolítica, favorecia o debate público em torno de temas rawlsianos e habermasianos, como razão pública, contratualismo, processos de aprendizagem da democracia e políticas públicas deliberativas. Os déficits normativos da antiga sociologia marxista e da teoria crítica da primeira geração (Adorno, Horkheimer, Marcuse), que foram amplamente explorados durante o regime autoritário, sobretudo pela esquerda e por movimentos de libertação, propiciaram uma nova problematização da normatividade em busca de justificativas para a ação racional que visa à promoção do bem comum. Assim como Giannotti introduzira com justeza a metáfora do contrato como jogo social de linguagem e Brum Torres consagrara a "lei de Gérson" como parte integrante de um modus vivendi comum a políticos e cidadãos em nosso ethos social, Boeira argumenta de forma convincente em favor da formulação autóctone de uma concepção pública de deliberação e processos decisórios para a implementação de políticas sociais e procedimentos na administração pública (Giannotti, 1991a, pp. 9-29; Brum Torres, 1992, pp. 165-178; Boeira, 2003, pp. 47-73). O contratualismo em Rawls e a reconstrução pragmático-formal da teoria crítica em Habermas podiam ser reformulados para proceder a uma abordagem contextualizada que parta de uma situação concreta de desigualdades e conflitos socioeconômicos, com o desideratum de eventualmente integrar questões normativas com os problemas metafísicos do eu e da identidade pessoal num mesmo nível de argumentação justificatória. $\mathrm{O}$ nosso problema continua sendo o de justificar em termos normativos a formulação de critérios procedimentais, embasados em nossa complexa realidade social e que sejam capazes de implementar medidas justas que contribuam para tornar a nossa sociedade mais igualitária e equitativa. Tanto para Rawls quanto para Habermas permanece o grande desafio de articular teoria e prática, dada a dificuldade - para muitos, a impossibilidade - de colocar em prática o que Rawls chamou de 
$|18|$

Debate Público e Filosofia no Brasil...

"pluralismo razoável" ou de um "agir comunicativo" sem distorções ou manipulações de uma das partes - segundo a ideia habermasiana de "situação ideal de fala".

A obra-prima de Rawls tem sido consensualmente avaliada como a mais importante e original contribuição em ética, filosofia do direito e filosofia política na segunda metade do século passado. Hoje, passados mais de quarenta anos desde a sua publicação, A Theory of Justice permanece um dos mais importantes marcos teóricos para pensarmos o futuro da democracia no mundo inteiro - não apenas em sociedades liberais consolidadas mas ainda em democracias emergentes, como a nossa própria democracia brasileira e a de tantos outros países emergentes, na América Latina, na Europa do Leste, na Ásia e na África. Decerto uma avaliação mais justa e precisa dessa obra em particular nos remete às modificações feitas pelo próprio autor na revisão do texto original para a versão alemã em 1975, assinaladas nos prefácios que ele mesmo redigiu para as edições francesa (1987) e brasileira (1990) e sobretudo nos escritos em torno do construtivismo kantiano e do liberalismo político, seguindo as Dewey Lectures de 1980. Se quisermos resumir em uma única palavra em que consiste a grande inovação de Rawls para justificar em termos normativos sua concepção filosófica de democracia constitucional em nossos dias, podemos sugerir o seu conceito de construtivismo correlato ao procedimentalismo que caracteriza o seu liberalismo político e constitucionalismo efetivo. Interessantemente, tal conceito de construtivismo não foi explicitamente desenvolvido em seu texto de 1971, onde o termo não ocorre, mas é pressuposto na medida em que a proposta rawlsiana é entendida como um modelo construtivista de justificativa ético-normativa da justiça social em contraposição a modelos intuicionistas. Podemos tratar de problemas metaéticos e normativos do construtivismo em torno do chamado "argumento da congruência" (congruence argument), supostamente abandonado por Rawls em 1993, quando reconheceu a impossibilidade de justificar a primazia do justo sobre o bem para abandonar uma concepção abrangente da justiça como equidade em favor de uma concepção especificamente política de justiça 
social. O problema metaético do argumento da congruência consiste em afirmar, por um lado, a primazia do justo sobre o bem, segundo um construtivismo moral não intuicionista e antirrealista, ao mesmo tempo em que acaba por favorecer um construtivismo político e uma ideia de autonomia política para viabilizar o consenso de sobreposição capaz de abrigar diferentes doutrinas abrangentes, dado o fato do pluralismo razoável. O problema aparentemente incontornável, segundo o próprio Rawls, consiste em que uma sociedade bem-ordenada poderia incluir também indivíduos razoáveis que eventualmente rejeitariam a interpretação kantiana e o papel fundamental acordado à autonomia moral e, consequentemente, à primazia do justo sobre o bem. Creio que encontramos aqui o aporético problema da fundamentação moral do direito e do político, que perduram nas tentativas de autores contemporâneos como Rawls e Habermas em seus engenhosos esforços de reabilitar um modelo deontológico de inspiração kantiana para justificar o universalismo ético-normativo em resposta aos desafios do relativismo cultural. Na recepção crítica do debate filosófico brasileiro, a questão normativa tem sido mais frequentemente explorada em termos procedimentais, processuais ou de interesse jurídico-administrativo, justamente pela falta de transparência, reciprocidade, igualitarismo e imparcialidade em muitas de nossas instituições sociais e governamentais.

3. Vários pensadores brasileiros propuseram uma reconstrução da ética do discurso à luz da teoria habermasiana da democracia deliberativa como uma transformação hermenêutica da chamada "interpretação kantiana" do equilíbrio reflexivo de Rawls. Se, por um lado, Habermas quer evitar uma redução dos agentes morais e atores sociais a meros clientes de um sistema reificador de mundos sociais, por outro lado, ele também procura evitar as aporias kantianas de concepções normativas como a do equilíbrio reflexivo rawlsiano. Ademais, as formas comunicativas desempenham, para Habermas, um papel catalisador e revitalizador da própria concepção fenomenológico-hermenêutica de mundo da vida. Como não há socialização humana sem razão e agir 
$|20|$

Debate Público e Filosofia no Brasil...

comunicativos, na medida em que estes constituem o próprio meio (medium) para a reprodução de mundos da vida, a interação orgânica entre consenso normativo e sistema institucional inerente a processos decisórios de uma democracia deliberativa nos remete desde sempre a uma correlação entre linguagem, ontologia e intersubjetividade. A pesquisa social interdisciplinar em nosso país se insere, portanto, num âmbito mais amplo de questionamento filosófico, a saber, se ainda e em que medida podemos recorrer de modo consistente e defensável a uma argumentação quase transcendental como sugere Habermas. Seguindo uma intuição de Hans Joas em sua resenha da coletânea de Habermas "Entre Naturalismo e Religião" ("Die Religion der Moderne", Die Zeit, 13.10.2005) pode-se asserir que todo o seu projeto pós-metafísico tenta dar conta da normatividade correlata aos horizontes do observador e do agente moral/ator social, desde as investigações seminais sobre a lógica das pesquisas sociais no final dos anos 1960 até as suas formulações de teorias discursivas da democracia e do direito nos anos 1990. Segundo tal "dualismo de perspectivas", Habermas logra destarte integrar os últimos resultados de pesquisas empíricas do naturalismo (em biogenética, neurociências, inteligência artificial, ciências cognitivas, biologia molecular) aos legados filosóficos e culturais tradicionalmente associados a reflexões sobre a normatividade inerente a relações intersubjetivas do mundo da vida.

De acordo com Habermas, a questão da normatividade moral (formulada pela ética do discurso) deve ser articulada com a questão social e política da institucionalização de formas de vida, na própria concepção de um modelo integrado diferenciando o mundo sistêmico das instituições (definido pela capacidade de responder a exigências funcionais do meio social) do mundo da vida (i.e., das formas de reprodução cultural, societal e pessoal que são integradas através de normas consensualmente aceitas por todos os participantes). A grande questão que motiva tal modelo dual da sociedade é, para Habermas, a de dar conta dos complexos processos de reprodução social - material e simbólica - em seus diversos níveis de integração social, reprodução cultural e socialização 
interpessoal em face de mecanismos estruturais de controle notavelmente, poder e dinheiro -, tais como os encontramos hoje na chamada globalização dos mercados econômicos e financeiros. Habermas procura, ao mesmo tempo, evitar um determinismo econômico (da Überbau pela Unterbau, na terminologia marxista) e acatar as contribuições sociológicas (em particular, de Weber, Durkheim e Parsons) para uma compreensão dos processos de diferenciação social, cultural e política, sem incorrer em formas sutis de funcionalismo. A hipótese de trabalho que guia essa investigação é mostrar em que medida a concepção habermasiana de mundo da vida logra preservar o conceito kantiano de autonomia num nível público de normatividade e universalizabilidade, ao justificar a integração e a diferenciação de instituições tais como a família, a sociedade civil, o estado e organizações governamentais e não governamentais, com relação aos subsistemas econômicos, políticos e administrativos. Assim, a facticidade do mundo da vida, em particular, expressa numa cultura política democrática pluralista, deve ser compreendida de maneira correlata à normatividade e validade da autonomia pública, de forma a superar a atual crise paradigmática da democracia, especialmente a crise de legitimação que caracteriza o estado moderno, sem incorrer nas aporias de uma crítica da ideologia ou diferentes versões de relativismo, ceticismo e historicismo em filosofia política. Pelo seu procedimentalismo kantiano, a concepção habermasiana de democracia participativodeliberativa se propõe como uma alternativa aos modelos liberais (especialmente, Rawls) e comunitaristas (neoaristotélicos, neohegelianos, neomarxistas). A fim de evitar a autorreferencialidade da razão prática kantiana (o "fato da razão"), Habermas reconcebe a "autonomia pública" como a disponibilidade de uma rede diferenciada de arranjos comunicativos para a formação discursiva da vontade e opinião pública, na medida em que um sistema de direitos individuais básicos fornece exatamente as condições para que as formas de comunicação necessárias para uma constituição do direito politicamente autônoma sejam assim institucionalizadas. No entanto, apesar de sua construção intersubjetiva do mundo 
$|22|$

Debate Público e Filosofia no Brasil...

social, a teoria habermasiana parece incorrer em generalizações de concepções empíricas de subjetividade, notavelmente na formulação de uma identidade coletiva, na própria autocompreensão de cultura em suas dimensões estética, moral e política. Segundo Habermas, os fundamentos necessários para uma autodeterminação capaz de realizar o projeto modernista de emancipação, embasado na razão e ação comunicativa, devem integrar a vida social cotidiana e exigem, portanto, um engajamento da sociedade civil, através da participação política, associações voluntárias, movimentos sociais e desobediência civil, no processo de busca de entendimento mútuo em juízos de validade. É precisamente neste rapprochement crítico entre um nível comunicativo-discursivo e um nível sociopolítico da ação coordenada - níveis inseparáveis da vida prática intersubjetiva que Habermas logra efetivar uma verdadeira guinada linguísticopragmática em filosofia política.

4. Na mesma esteira das recepções críticas de Rawls e Habermas, os aportes filosóficos da teoria de Amartya Sen são reexaminados de forma a justificar uma concepção de justiça igualitária, em função do valor moral substantivo da liberdade, assegurando a estabilidade e a legitimidade das sociedades, o atendimento das necessidades humanas e a consolidação da estrutura democrática, sem a qual não se podem fundamentar as condições de igualdade e de justiça social. Trata-se de uma reafirmação do ideal de justiça como meta mais fundamental e importante da organização social de nossas democracias liberais, na medida em que denuncia e procura reduzir as desigualdades que persistem no capitalismo tardio e que são ainda mais acentuadas com a globalização no século XXI. Com efeito, o aumento da produção de bens, da inovação tecnológica e da capacidade de comunicação serve apenas para corroborar ainda mais as contradições e patologias sociais que ameaçam a legitimidade e a estabilidade políticas, a coesão social, a robustez econômica e a própria identidade cultural de povos e nações em países emergentes, assim como também em países desenvolvidos, com as constantes ondas de migrações, desemprego massivo, crises 
financeiras e ameaças terroristas. Destarte, observa-se um desequilíbrio nas relações entre as pessoas e entre os países, decorrente desse descompasso entre as expectativas pessoais e um ordenamento social que prioriza o acesso aos bens, a maximização da liberdade individual e a racionalização embasada na utilidade.

Trata-se, portanto, de reformular em termos sustentáveis o conceito de desenvolvimento humano, na medida em que se mostra inseparável das oportunidades concretas a serem criadas pelos governantes de uma nação, propiciando à população a real possibilidade de fazer escolhas e exercer a sua cidadania livremente. Para tanto, devem ser assegurados não apenas os direitos sociais básicos, como saúde e educação, como também segurança, liberdade, habitação, cultura e o acesso de todos à justiça. De acordo com Sen, somente o valor moral substantivo da liberdade possibilitaria o reconhecimento da pluralidade e a necessidade de atuação não limitada às fronteiras territoriais, favorecendo, assim, a construção de uma verdadeira justiça global. Se a democratização e a globalização parecem consolidar hoje, mais do que nunca, um universalismo mitigado ao alcance de todos os que subscrevem aos direitos humanos e seus ideais de igual liberdade estendidos a todas as pessoas, cabe a cada povo e a cada nação lutar para que tais aspirações e reivindicações sejam realizadas. Afinal, como insinuava Rawls, uma democracia sem igual liberdade e sem igualdade equitativa de oportunidades seria simplesmente insustentável. A estabilidade política de nossas instituições sociais depende efetivamente da moralidade da coisa pública, da sua transparência, publicidade, reciprocidade e equidade. E a própria ideia de equidade deve ser concretamente refletida nos proventos e na distribuição equitativa de bens primários, começando com a autoestima e a educação pública de qualidade. Sem educação, não há cultura política nem democracia que se sustente: as políticas públicas e todo projeto de melhorias sociais no nosso país exigem uma base pedagógica democrática, transparente e participativa. Ora, todos nós sabemos que o tecido social brasileiro está ameaçado pela ineficiência e pela falta de credibilidade moral nos três poderes e nas esferas municipais, estaduais e federais de gestão pública. 
$|24|$

Debate Público e Filosofia no Brasil...

Quando os juízes federais entram com uma ação no Supremo Tribunal Federal para aumentar os próprios salários, quando se propõe o aumento dos vencimentos de ministros e servidores públicos ou quando se questiona o piso salarial ou se propõem cortes de gastos públicos com educação e saúde, ao mesmo tempo em que se proliferam os cargos de confiança e despesas públicas moralmente suspeitas, sabemos que o país vive momentos decisivos para a consolidação de seu ethos democrático e de um igualitarismo sustentável. Não há desenvolvimento sustentável nem igualitarismo democrático num país onde deputados, senadores e magistrados ganham salários 20 ou até 40 vezes maiores do que a maior parte das professoras e professores dos ensinos fundamental e médio. O debate público em torno de problemas de filosofia política pode efetivamente contribuir, outrossim, para que um número cada vez maior de cidadãos neste país se engaje na luta da sociedade civil contra as desigualdades, injustiças e patologias sociais que persistem em nossa democracia. Em última análise, podemos contribuir para a democratização pela implementação de políticas públicas e pela deliberação de propostas razoavelmente defensáveis e exequíveis visando à promoção efetiva dos nossos direitos sociais e das nossas liberdades substantivas e à redução de desigualdades econômicas e sociais.

5. Assim como Giannotti e Loparic foram importantes interlocutores críticos quando da visita de Habermas ao Brasil (Giannotti, 1991b, pp. 7-23; Loparic, 1990, pp. 111-116), também foram produzidos interessantes trabalhos que visavam uma devida resposta crítica a desafios teóricos do pensamento filosófico-político contemporâneo. O mais recente livro de Denis Lerrer Rosenfield, Justiça, Democracia e Capitalismo (Rosenfield, 2010), se insere nesse tipo de interlocução crítica e polêmica, ao tratar de três temas interligados, mostrando que a democracia e o capitalismo têm como pressuposto comum a liberdade de escolha, correlata à própria ideia de justiça, concebida não num sentido de igualitarismo social, mas no sentido kantiano de princípio de universalizabilidade, viabilizando o exercício democrático da liberdade e o 
desenvolvimento do capitalismo. Além de tematizar problemas rawlsianos que haviam sido negligenciados na "recepção de esquerda" - como o da propriedade privada (que o próprio Rawls deixou em aberto no texto de 1971), o da estabilidade políticoinstitucional e o da congruência entre o justo e o bem -, Rosenfield procura fazer jus à democracia e ao capitalismo na mesma proporção em que estes se revelam correlatos e inseparáveis nas suas concepções e realizações históricas e efetivas. Assim como Paul Ricoeur, Denis Rosenfield opera um verdadeiro retorno póshegeliano a Kant em sua defesa da liberdade da ação humana como valor fundamental a ser conservado, acima de tudo, inclusive se quisermos assegurar a experiência histórica da sociabilidade pluralista. Em contraste com o socialismo religioso de Ricoeur e liberacionistas latino-americanos, Rosenfield reabilita a ética da responsabilidade individual e social inerente ao capitalismo e seu poder transformador de "destruição criadora", segundo a frase lapidar de Schumpeter (p. 9). Assim como Rawls e Habermas, Rosenfield configura a articulação entre justiça, democracia e capitalismo dentro do espaço discursivo da razão prática, pautado pela publicidade, pela transparência e pela coerência dos argumentos deliberativos. Ao contrário de Rawls e Habermas, entretanto, Rosenfield rejeita o procedimentalismo e o igualitarismo em favor de um libertarismo virtuoso capaz de transformar os "supostos vícios privados em benefícios públicos" (p. 190).

Destarte, a própria ideia de democracia, segundo Rosenfield, deve ser revisitada a partir da sua gênese capitalista-liberal moderna e não desde uma perspectiva socialista de justiça social, levando em conta experiências, conceitos e vivências da sociedade brasileira concreta. O grande desafio de articular um nível empírico descritivo da sociedade e suas instituições sociais, econômicas, jurídicas, políticas e administrativas com os valores e pilares normativos da vida cotidiana é vislumbrado pelo professor Rosenfield através de um diagnóstico meticuloso da democracia brasileira, suas contradições, realizações e promessas, de forma a justificar de modo convincente quais seriam os rumos a serem tomados para assegurar o desenvolvimento do país e a liberdade de seus cidadãos. Sem 
$|26|$

Debate Público e Filosofia no Brasil...

um capitalismo robusto não há florescimento da democracia e sem um regramento justo da democracia o capitalismo se torna insustentável. Afinal, sem a efetiva realização da democracia embasada na liberdade individual e nos ideais do liberalismo clássico e sem o desenvolvimento do capitalismo europeu, o mundo ocidental não teria cristalizado o processo de evolução social que viabilizou todo o progresso científico e tecnológico assegurando qualidade de vida para grande parte da humanidade.

Assim como não se deixa reduzir ao voto popular nem mesmo à liberdade de opinar contra os abusos perpetrados pela má gestão da coisa pública, a democracia não pode prescindir de regras e ordenamentos institucionais embasados no valor moral da vida humana e das liberdades individuais, que devem ser protegidas e promovidas, bem como o direito de propriedade e do respeito aos contratos. Sobretudo em nosso país, onde já estamos acostumados a reclamar da corrupção, da ineficiência e da arbitrariedade de órgãos governamentais e de representantes atuando nos três poderes, em nossos municípios, nos estados e na União, sem, no entanto, entendermos por que será que as coisas continuam sendo exatamente como eram há dez ou mais anos. Não basta promover inovações semânticas ou ressignificações de velhos conceitos populistas. Segundo Rosenfield, é mister revisitar a coerência de regramento entre os direitos e os valores normativos que defendemos em nossa democracia e as regras do jogo no capitalismo, não apenas respeitando o direito de propriedade e as liberdades individuais de iniciativa e empreendimento, mas incentivando a inovação e a criatividade empreendedoras através da não intervenção paternalista de um Estado provedor. Um Estado que se preocupa em ditar o modo de vida e as crenças básicas de seus cidadãos não é democrático-liberal. Um estado democrático que não promove a justiça através de procedimentos e regras universais, transparentes e eficientes não é de direito. Como lembra o professor Rosenfield, "regras jurídicas, enquanto regras sociais, devem ser observadas enquanto regras que garantem a sociabilidade". E, parafraseando Mandeville, exorta a administração pública a 
retomar uma atitude de "tolerância zero" com o fito de restabelecer a justiça mostrando, de forma contundente, que "ações criminosas, de quaisquer tipos, não ficarão impunes" (p. 189).

Na medida em que se tornou uma forma de gestão criativa, inovadora e sustentável do capitalismo e não da sua eliminação, "a social-democracia não é socialista, mas capitalista" (p. 65), segundo a tese central enunciada no livro do professor Rosenfield de maneira tão lapidar quanto polêmica. As suas críticas sistemáticas a movimentos populistas dos quilombolas e dos trabalhadores rurais sem-terra visam denunciar os abusos demagógicos cometidos em nome de direitos humanos que acabam por obscurecer o sentido originário da justiça, desmoralizar o estado democrático de direito e por enfraquecer o potencial humanizador do capitalismo. $\mathrm{O}$ agir instrumental e o utilitarismo de resultados frequentemente atribuídos a programas neoliberais acabam por ressignificar os contextos de validade das reivindicações de direitos humanos e dos programas sociais de ação afirmativa e de distributivismo igualitário, produzindo verdadeiras inversões semânticas através do ativismo manipulador de militantes da esquerda brasileira.

Esquecemos, segundo Rosenfield, que a democracia "é tida por um valor universal, um fim em si mesmo, e não algo que pode ser instrumentalizado para colocar em seu lugar um regime liberticida" (p. 65). Em última análise, devemos sempre nos lembrar que os "princípios que tornam a sociabilidade humana algo frutífero para todos" nos remetem à própria convivência entre pessoas, que embora diferentes e buscando projetos de vida diferenciados, são igualmente detentoras de direitos e deveres. Ora, como conclui Rosenfield, "a liberdade de escolha é um desses princípios fundadores da convivência, pois é ela que faz com que as pessoas se respeitem e tenham um comum apreço por algo que é reconhecido como tendo validade universal. Podemos ter divergência no que diz respeito aos objetos de nossas respectivas liberdades, porém não deveríamos ter no que concerne ao princípio da liberdade enquanto tal" (p. 247). 
$|28|$

Debate Público e Filosofia no Brasil...

6. À guisa de conclusão, lembramos que a questão brasileira da transição para a democracia foi sistemática e incisivamente debatida por pesquisadores, historiadores, intelectuais e cientistas sociais ligados ao CEBRAP e às universidades de Yale e Columbia, entre 1983 e 1987, resultando na confecção de um volume, Democratizing Brazil, editado pelo "brasilianista" Alfred Stepan. $\mathrm{Na}$ verdade, o volume dava continuidade a uma análise aprofundada dos problemas sociais, políticos e econômicos que assolaram o Brasil durante a ditadura militar, traduzida pela elaboração de um outro volume, Authoritarian Brazil, entre 1971 e 1972, no zênite do autoritarismo (Stepan, 1973 e 1989). A passagem do regime militar a um regime civil presidencialista em março de 1985 assinalou o início de um verdadeiro processo de democratização e de reconstrução do espaço público, para além dos jargões da longa era ideológica da Guerra Fria - mas no interior da qual toda análise discursiva deveria ser então empreendida. É muito oportuno lembrar também que o discurso liberacionista - não apenas das chamadas teologias da libertação, mas ainda dos movimentos estudantis e das transformações socioculturais dos anos 1960 e 1970 - foi elaborado como uma resposta crítica e alternativa à doutrina liberal e capitalista do desenvolvimentalismo (muito antes de Amartya Sen ou da febre global de "desenvolvimento sustentável", agora adotada por dirigentes latino-americanos), segundo a qual seria apenas uma questão de tempo para que alguns países do chamado Terceiro Mundo "decolassem" (take off) definitivamente rumo ao desenvolvimento (desarrollo) - daí a terminologia dos developing countries, "países em desenvolvimento". Lembramos ainda que a emergência da teoria rawlsiana da justiça em 1971 coincide com o mesmo ano em que Gustavo Gutiérrez publica sua Teología de la Liberación, de forma a argumentar em favor do princípio liberal da tolerância como alternativa às limitações de modelos desenvolvimentistas e liberacionistas para tratar da democratização em sociedades ditas "emergentes". Segundo a mais recente terminologia do "desenvolvimento sustentável", num mundo cada vez mais globalizado, uma transition to democracy 
deixa de ser apenas um fenômeno inevitável mas torna-se agora uma questão de sobrevivência. Para além dos debates e dos programas pautados por megaeventos internacionais, apoiados pela ONU e por ONGs do mundo inteiro, questões de direitos humanos e problemas afins entram definitivamente na agenda de processos decisórios em foros públicos globais, visando à implementação de políticas econômicas, em particular políticas públicas que lidam com questões referentes ao combate sistêmico de mecanismos de exclusão social. Por exemplo, as reivindicações de movimentos negros e feministas, grupos ecológicos, movimentos gay, grupos indígenas e outros atestam hoje a inevitabilidade de se aprofundarem as relações de solidariedade e alteridade para o pleno exercício da cidadania: o igualitarismo se manifesta cada vez mais pela diversidade do pluralismo democrático. E isso também se dá, paradoxalmente, nas relações entre culturas de países diferenciados econômica e socialmente. Assim, a própria concepção de "justiça global", correlata imediata da democratização num mundo globalizado, surge como uma proposta capaz de responder aos anseios de teorias liberacionistas, como a teoria da dependência de Cardoso-Faleto, na medida em que denuncia a colonização sistêmica do mundo da vida, sobretudo pelos monopólios do poder e do dinheiro (por exemplo, na política externa americana e nos efeitos nefastos do mercado financeiro) ou defende a transparência pública dos meios de acesso social à justiça pública estatal. É nesse contexto teórico-político com intento prático-pragmático que deveríamos reexaminar hoje os mecanismos e instrumentos de controle social do Poder Judiciário, através dos mais variados setores da vida nacional, tanto públicos quanto privados, de forma a integrar questões de natureza técnico-instrumental com problemas de filosofia política e teoria do direito. A urgência de tornar o Judiciário "transparente" e "acessível" ao contribuinte não se reduz a negociações políticopartidárias mas diz respeito a todo um processo de amadurecimento de nossa cultura política democrática. Como dizia um filósofo municipal paulista, o Direito é a Ideologia Brasileira por excelência - assim como Marx identificara o idealismo 
|30|

Debate Público e Filosofia no Brasil...

hegeliano como Die Deutsche Ideologie em seu tempo. Assim como o impeachment do presidente Collor se produziu num contexto democratizante de "ética na política" num estado democrático de direito, toda a efetiva transformação de instituições e práticas sociais, econômicas e políticas deve seguir as regras do jogo democrático, daí a concepção do procedimentalismo contratual no modelo rawlsiano. Segundo a lapidar formulação de Denis Rosenfield (1992, p. 32),

\begin{abstract}
As regras constitutivas da democracia não são dadas pela tradição, que funcionaria como uma espécie de limite, como um ponto de referência estável a pautar toda ação. As regras democráticas são produzidas pelos homens, regras que estes se deram no transcurso da história. Ou seja, estas regras têm somente como ponto de referência o seu próprio processo de constituição, nenhuma justificação externa a ela sendo de alguma valia. A democracia depende da ação livre que a institui e reitera cotidianamente, nada podendo ser deixado ao acaso ou à história, não havendo um mecanismo independente dos homens que asseguraria o seu funcionamento.
\end{abstract}

\title{
Bibliografia
}

BOEIRA, N. "Sobre a deliberação em questões públicas". In: OLIVEIRA, Nythamar Fernandes de e SOUZA, Draiton Gonzaga de (orgs.). Justiça e Política. Homenagem a Otfried Hoffe. Porto Alegre: EDIPUCRS, 2003.

BRUM TORRES, J. C. "Discutindo a Lei de Gérson". In: ROHDEN, Valério (org.). Racionalidade e Ação: Antecedentes da Filosofia Prática Alemã. Porto Alegre: Ed. Goethe-Institut, 1992.

GIANNOTTI, J. A. "Contrato e Contrato Social". Filosofia Política 6, 1991a. 

31, 1991b.

LOPARIC, Z. "Habermas e o terror prático", Manuscrito. Revista Internacional de Filosofia, v. XIII, n. 2, 1990.

ROSENFIELD, D. A ética na política. São Paulo: Brasiliense, 1992. Justiça, Democracia e Capitalismo. Rio de Janeiro: Elsevier, 2010.

STEPAN, A. Authoritarian Brazil: Origins, Policies and Future. New Haven: Yale University Press, 1973.

(org.). Democratizing Brazil: Problems of Transition and Consolidation. New York: Oxford University Press, 1989. 